\title{
Physics based modelling of tree fires and fires transitioning from the forest floor to the canopy
}

\author{
$\underline{\text { K. A. M. Moinuddin }}^{\text {a,c }}$ and D. Sutherland ${ }^{\text {a,b,c }}$ \\ ${ }^{a}$ Centre for Environmental Safety and Risk Engineering, Victoria University, Victoria \\ ${ }^{b}$ Department of Mechanical Engineering, University of Melbourne, \\ ${ }^{c}$ Bushfire and Natural Hazards Cooperative Research Centre. \\ Email: khalid.moinuddina@vu.edu.au
}

\begin{abstract}
Wildland fires or bushfires can be a surface fire such as a grassfire or an elevated crown fire. Crown fires are often supposed to originate from surface fires spreading either along the bark of the tree trunks or direct flame contact to low branches with leaves and needles. In a previous study, surface fire (grassfire) spread simulation was successfully conducted using a physics based model, Wildland Urban Interface Fire Dynamics Simulator (WFDS). The base open-source code of WFDS was developed by the National Institute of Standard and Technology (NIST), USA from its original building fire model Fire Dynamics Simulator (FDS); but it is being further developed by other researchers. It is important that the capabilities of WFDS for modelling tree and forest canopy fire are explored to develop rate of spread equations for crown fires.
\end{abstract}

In this study, we have first quantitatively studied a burning single tree and then semi-quantitatively studied forest floor fire transitioning to a crown fire. For tree burning simulations, Douglas fir experiments conducted at NIST are considered, where mass was measured and mass loss rate (MLR) was calculated taking into consideration the moisture content in the samples. We have used two thermal degradation submodels within the physics-based model to simulate the tree burning experiments the linear and Arrhenius models.

The aim of the first part is twofold: one we seek numerically converged results, which were elusive with the previous version of the model; and secondly we appraise two thermal degradation sub-models. Comparison of MLR results from the simulations shows that grid convergence is not elusive and convergence is deemed to be obtained with $50 \mathrm{~mm}$ grid for both thermal degradation sub-models. The grid converged solution agrees well with the experimental result involving burning of a Douglas fir tree.

Then a fire in a hypothetical forest of Douglas Fir trees sitting on a grassland, which can be thought of as a model of a plantation, is simulated using the linear thermal degradation sub-model due to its simpler parameterization requirement. A sensitivity of the domain height and space downstream of the forest is carried out. Final results are obtained with a narrow simulation domain of $124 \mathrm{~m}$ long, $8 \mathrm{~m}$ wide and $25 \mathrm{~m}$ high, which is not sensitive to domain size variation. The result, firstly, shows that the WFDS model is capable of qualitatively predicting propagation of surface fire to this forest canopy. It is also found that upon transitioning to a crown fire, after an adjustment period, a fire propagating with a quasi-steady rate of spread is established. We can therefore be confident that crown fire simulations and studying detailed crown fire dynamics are possible with the physics-based model.

Analysis of the heat release rate (HRR) data shows that the surface fire propagates underneath the crown fire and therefore the fire observed here is a supported crown fire. That is, the surface fire puts energy into the crowns to sustain the burning of the crown material. Overall many features are qualitatively in agreement with other crown fire studies.

By changing the properties and configuration of the fuel material, simulation of native Australian vegetation can be attempted. In the future, similar simulations will lead to greater understanding of the transition of surface fires to crown fires. With further refinement, simulations could be used to construct threshold models of crown fire transition. The largest drawback of physics based simulations remains the large computational time due to the extremely fine grid sizes required. However, a simple linear parameterisation of thermal degradation model along with simple turbulence model can be used to reduce some of the computational effort.

Keywords: $\quad$ Physics based modelling, crown fire, tree fire, fire transition, rate of spread 


\section{INTRODUCTION}

Wildland fires can have devastating effects on the community, economy and infrastructure. The fires can also impact on the viability of the surrounding areas. This includes disruption in water supplies due to erosion and contaminants caused by the fires. The incidence of fires attracts much public concern and fires are given considerable attention by the media due to their devastating effects. This is exemplified by the cases of Black Saturday (2009) and Ash Wednesday (1983) in Australia and the 2009 bushfires in Athens and Los Angeles. Therefore it is important to conduct studies on the behaviour of fire spread, although this proves extremely difficult since the sizes and rate of spread depends on numerous factors.

In a previous study Moinuddin et al. (2017), grassfire spread simulation was successfully conducted using physics based model, Wildland Urban Interface Fire Dynamics Simulator (WFDS). It is important to explore the extension of previous studies to tree and forest canopy fire. In this study, we have first studied a single tree burning quantitatively, following Mell et al. (2009). Then we have semi-quantitatively studied forest floor fire transitioning to a crown fire and the forward advancing behaviour of the crown fire.

For the tree burning simulations, the experiments of Douglas fir burning conducted at National Institute of Standard and Technology (NIST) are considered (Mell et al., 2009). During these experiments, 2.25m high trees were mounted on custom stands and allowed to dry. The $2.25 \mathrm{~m}$ trees were separated into two groups with average moisture content by mass of $14 \%$ and $49 \%$. Trees were ignited using a circular natural gas burner with a specific heat release rate of $30 \mathrm{~kW}$. The mass of the sample tree was measured and the mass loss rate calculated taking into consideration the moisture content in the samples. In our simulations we have used two thermal degradation sub-models to simulate tree burning - WFDS (linear) (Mell et al, 2007, Mell et $a l, 2009$ ) and Fire Dynamics Simulator, FDS (simplified Arrhenius) (McGrattan et al. 2008). FDS is the original building fire model developed by NIST. Both models have the same fluid flow, turbulence, continuity, pressure, energy, radiative heat transfer and combustion models. They also simulate the fuel distribution in a similar, but not identical, manner. The main difference is in thermal degradation sub-model which will be discussed in the next section.

After replicating experiments of Douglas fir burning using two models, we aim to model fire behaviour with the more suitable model in a forest of Douglas Fir trees sitting on a grassland - a hypothetical scenario which can be thought of a plantation. The behaviours include transition from surface fire to crown fire, forward advancing of both crown fire and surface fire etc.

\section{MODEL OVERVIEW AND ITS INPUT PARAMETERS}

WFDS and FDS use a Computational Fluid Dynamics (CFD) methodology to solve the governing equations for buoyant flow, heat transfer, combustion, and the thermal degradation of vegetative fuels and Large Eddy Simulation (LES) techniques are used to account for turbulence (Mell et al. 2007). The model aims to include fire spread through vegetative fuels. Vegetative fuels can include those characteristic of bushlands i.e. trees, grasses, understory growth, and ground litter as well as those purchased at nurseries for home or community landscaping purposes such as trees, mulch, grasses, and decorative plants.

\subsection{Fuel (vegetation) model}

The models have two ways of modelling vegetative fuels, namely (i) the fuel element (FE) model for vegetation that occupies a specified volume such as trees (for example, Douglas fir trees are modelled as cones (Mell et al. 2009)) and (ii) the boundary fuel (BF) model for surface fuels such as grasslands (Moinuddin et al. 2017).

With the FE model, trees can be modelled with various shapes: cone, frustum, cylinder and rectangle. Table 1 gives other physical parameters needed for the tree fire simulation. In the FE model, there is no distinction between solid phase and gas phase grid. The grid resolution is the same for both phases. The fuel distribution within the tree (ie the leaves and twigs) is modelled as a cloud of burnable particles with the specified properties.

The BF model treats fuel as a flat bed and above this the domain is used for gas phase. Within the fuel bed a sufficiently high spatial resolution is used to capture the vertical radiant heat transfer. However, the horizontal grid is the same as the gas phase and the accuracy of convective heat transfer will be heavily influenced by the gas phase grid resolution. The assumptions leading to the BF model are most consistent with large fires for which the majority of the heat release (and, therefore, radiant emission) occurs above the fuel bed (resulting in predominantly vertical radiant heat transfer in the thermally degrading fuel bed). 
Moinuddin et al., Physics based modelling of tree fires and fires transitioning from forest floor canopies

Table 1. Physical parameters used in WFDS

\begin{tabular}{|c|c|c|c|c|c|c|}
\hline Parameters & \multicolumn{4}{|c|}{ Values } & Units & \multirow[t]{2}{*}{ Description } \\
\hline & Needles & $0-3 \mathrm{~mm}$ & $3-6 \mathrm{~mm}$ & $6-10 \mathrm{~mm}$ & & \\
\hline Mass fraction & $63 \%$ & $13 \%$ & $10 \%$ & $14 \%$ & & \\
\hline TREE & \multicolumn{5}{|c|}{ Text } & .TRUE. for vegetation particles. \\
\hline VEG_SV & 3940 & 2667 & 889 & 500 & $\mathrm{~m}^{-1}$ & Surface to volume ratio of the vegetation element \\
\hline VEG_MOISTURE & \multicolumn{4}{|c|}{0.14} & & $\begin{array}{l}\text { Moisture fraction (mass of moisture in vegetation/dry } \\
\text { mass of vegetation) }\end{array}$ \\
\hline VEG_CHAR_FRACTION & \multicolumn{4}{|c|}{0.25} & & $\begin{array}{l}\text { Fraction of char that develops from virgin dry virgin } \\
\text { vegetation }\end{array}$ \\
\hline VEG_DRAG_COEFFICIENT & \multicolumn{4}{|c|}{0.375} & & $\begin{array}{l}\text { Non-dimensional multiplicative factor used to model } \\
\text { drag }\end{array}$ \\
\hline VEG_DENSITY & \multicolumn{4}{|c|}{514} & $\mathrm{~kg} / \mathrm{m}^{3}$ & Vegetative fuel's density \\
\hline VEG_BULK_DENSITY & 1.66 & 0.34 & 0.26 & 0.37 & $\mathrm{~kg} / \mathrm{m}^{3}$ & $\begin{array}{l}\text { Density of the bulk vegetation; mass of dry vegetation } \\
\text { divided by the bulk volume that is containing the } \\
\text { vegetation }\end{array}$ \\
\hline VEG_REMOVED_CHAR & \multicolumn{4}{|c|}{ Text } & & $\begin{array}{l}\text { TRUE. or .FALSE.; whether the fuel element is } \\
\text { removed or kept once the thermal degradation has } \\
\text { converted the vegetation to pure char. Selected as } \\
\text { TRUE. }\end{array}$ \\
\hline FUEL_GEOM & \multicolumn{4}{|c|}{ Cone } & & $\begin{array}{l}\text { Shape of bulk volume that contains vegetation: } \\
\text { RECTANGULAR, CYLINDER, CONE, FRUSTUM }\end{array}$ \\
\hline CROWN_WIDTH & \multicolumn{4}{|c|}{1.65} & $\mathrm{~m}$ & $\begin{array}{l}\text { Diameter, measured in meters relative to } \mathrm{XYZ} \text { of the } \\
\text { top of the bulk vegetation if the shape is cone, } \\
\text { cylinder or frustum. }\end{array}$ \\
\hline CROWN_BASE_HEIGHT & \multicolumn{4}{|c|}{0.3} & $\mathrm{~m}$ & $\begin{array}{l}\text { Height, measured in meters relative to } \mathrm{XYZ} \text { of the } \\
\text { base or bottom of the bulk vegetation if the shape is } \\
\text { cone, cylinder or frustum. }\end{array}$ \\
\hline TREE_HEIGHT & \multicolumn{4}{|c|}{2.25} & $\mathrm{~m}$ & $\begin{array}{l}\text { Height, measured in meters relative to } \mathrm{XYZ} \text { of the top } \\
\text { of the bulk vegetation if the shape is cone, cylinder or } \\
\text { frustum }\end{array}$ \\
\hline
\end{tabular}

While BF model is the same in WFDS and FDS- the FE model is slightly different in FDS. In this study, the Douglas Fir tree crown is approximated as being cone shaped with four different sizes of particles in both models. In WFDS needles, 0-3mm branch, 3-6 $\mathrm{mm}$ branch and 6-10 $\mathrm{mm}$ branch are used and their properties are given in Table 1. Each component differs by surface to volume ratio and vegetation bulk density. On the other hand, in FDS we used: foliage (length $0.05 \mathrm{~m}$ and thickness $0.0005 \mathrm{~m}$ ), small roundwood (length $0.1 \mathrm{~m}$ and thickness $0.001 \mathrm{~m}$ ), medium roundwood (length $0.1 \mathrm{~m}$ and thickness $0.002 \mathrm{~m}$ ) and large roundwood (length $0.1 \mathrm{~m}$ and thickness $0.003 \mathrm{~m}$ ) and all with cylindrical shapes. There are 100,000 particles of each type per unit volume and bulk densities are 2.0, 0.4, 0.3 and $0.5 \mathrm{~kg} / \mathrm{m}^{3}$, respectively.

Table 2. Thermal parameters used in WFDS

\begin{tabular}{|l|l|c|}
\hline Variable & Values & Units \\
\hline HEAT_OF_COMBUSTION & 17,770 & $\mathrm{~kJ} / \mathrm{kg}$ \\
\hline SOOT_YIELD & 0.015 & $\mathrm{~kg} / \mathrm{kg}$ \\
\hline VEG_INITIAL_TEMPERATURE & 20 & ${ }^{\circ} \mathrm{C}$ \\
\hline HEAT_OF_VAPORIZATION & 2259 & $\mathrm{~kJ} / \mathrm{kg}$ \\
\hline HEAT_OF_PYROLYSIS & 416 & $\mathrm{~kJ} / \mathrm{kg}$ \\
\hline SPECIFIC_HEAT_CAPACITY & $1.11+0.0037 \mathrm{Ts}$ & $\mathrm{kJ} / \mathrm{kg} / \mathrm{C}$ \\
\hline VEGETATION_BURNING_RATE_MAX & 0.4 & $\mathrm{~kg} /\left(\mathrm{m}^{3} \mathrm{~s}^{1}\right)$ \\
\hline
\end{tabular}

Table 3. Thermal parameters used in FDS

\subsection{Thermal degradation model}

There are two models for thermal degradation: 'linear' and 'Arrhenius'. Both are based on empirical studies. The linear degradation model assumes a two-stage endothermic thermal decomposition (water evaporation and then solid fuel pyrolysis). For water evaporation, Eq 1 is used:

$$
\text { If } T_{s}=373 K, \dot{m}_{v a p}=\frac{\dot{Q}_{n e t}}{\Delta h_{v a p}}
$$

\begin{tabular}{|l|c|c|c|}
\hline Parameters & Moisture & Vegetation & Char \\
\hline Thermal conductivity $(\mathrm{W} / \mathrm{m} . \mathrm{K})$ & 2.0 & 2.0 & 2.0 \\
\hline Specific heat $(\mathrm{kJ} / \mathrm{kg} . \mathrm{K})$ & 4.184 & 1.2 & 1.2 \\
\hline Density $\left(\mathrm{kg} / \mathrm{m}^{3}\right)$ & 1000 & 514 & 300 \\
\hline REFERENCE_TEMPERATURE $\left({ }^{\circ} \mathrm{C}\right)$ & 100 & 200 & 350 \\
\hline REFERENCE_RATE & 0.002 & .0005 & 0.0002 \\
\hline HEATING_RATE $\left({ }^{\circ} \mathrm{C} / \mathrm{min}\right)$ & 1.6 & 1.6 & 1.6 \\
\hline HEAT OF PYROLYSIS $(\mathrm{kJ} / \mathrm{kg})$ & 2500 & 418 & 418 \\
\hline MASS FRACTION & 0.123 & 0.649 & 0.228 \\
\hline
\end{tabular}


where, $T_{s}$ is the vegetation surface temperature, $\dot{m}_{v a p}$ is the evaporation rate, $\dot{Q}_{n e t}$ is the net energy (convection plus radiation) on the fuel surface and $\Delta h_{v a p}$ is the latent heat of evaporation. It uses the temperature-dependent mass loss rate expression of Morvan and Dupuy (2004) (presented as Eq 2) to model the solid fuel degradation and assumes that pyrolysis begins at $400 \mathrm{~K}$.

$$
\text { If } 400 \mathrm{~K} \leq T_{s} \leq 500 \mathrm{~K}, \dot{m}_{\text {pyr }}=\frac{\dot{Q}_{\text {net }}}{\Delta h_{\text {pyr }}} \frac{T_{s}-400}{500-400}
$$

where, $\dot{m}_{p y r}$ is the pyrolysis rate and $\Delta h_{p y r}$ is the heat of pyrolysis (also known as the heat of reaction). With the Linear model, ignition and sustained burning occurs more 'easily' (i.e., at lower gas phase temperatures) because pyrolysis occurs over a lower temperature range. Because of this, coarser gas phase grid resolutions may be sufficient but requires that the user supply a boundary on the maximum mass loss rate per unit area or volume in the form of FIRELINE_MLR_MAX $\left(\mathrm{kg} / \mathrm{s} / \mathrm{m}^{2}\right)$, VEGETATION_BURNING_RATE_MAX $\left(\mathrm{kg} / \mathrm{s} / \mathrm{m}^{3}\right)$ or VEGETATION_DEHYDRATION_RATE_MAX $\left(\mathrm{kg} / \mathrm{s} / \mathrm{m}^{3}\right)$.

The 'Arrhenius' model used in WFDS/ FDS is described in (McGrattan et al. 2008) which employs a kinetic triplet to model thermal degradation. However FDS also has a simplified Arrhenius model which uses alternative parameters REFERENCE_TEMPERATURE, REFERENCE_RATE and HEATING_RATE. We have termed this here as "simplified Arrhenius" model and used for simulation using FDS version 6.2.0.

The required parameters to solve submodels in WFDS are presented in Tables 1 and 2. Thermo-physical parameters used in FDS simulation is presented in Table 3.

\section{RESULTS AND ANALYSIS}

\subsection{Douglas Fir tree fire -quantitative analysis}

The choice of the size of the grid (cell) in a mesh is one of the first and most important decisions one must make when conducting a quantitative simulation. The choice of grid size can affect the results. In conducting physics-based analysis it is essential to undertake a grid convergence study.

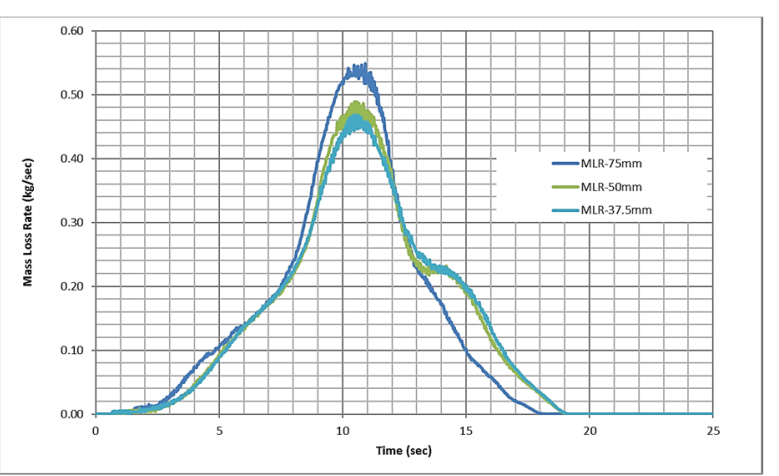

(a) WFDS_9977

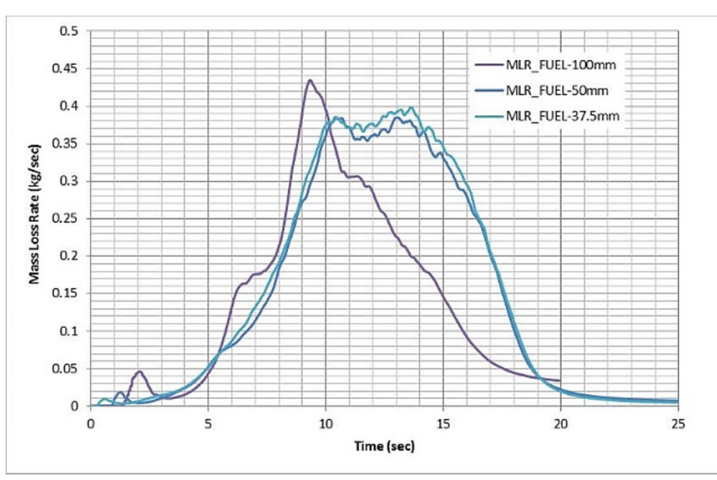

(b) FDS 6.2.0

Figure 1. Comparison of Mass loss rate (MLR) results for $2.25 \mathrm{~m}$ Douglas fir tree simulations for grid sizes: $75 \mathrm{~mm}, 50 \mathrm{~mm}$ and $37.5 \mathrm{~mm}$

The first step in a grid convergence study is to compare the Mass Loss Rate (MLR) or Heat Release Rate (HRR) results of similar simulations but with finer grid sizes. We conducted a similar study with WFDS's version 4 (Moinuddin et al. 2010) in terms of HRR and we found that grid convergence was elusive. However, the developers of FDS/WFDS claim that the current version (version 6) is less grid sensitive due to the use of an alternative LES model, a new near-wall model, a new combustion model, along with some bug-fixing. We have selected $75 \mathrm{~mm}, 50$ $\mathrm{mm}$ and $37.5 \mathrm{~mm}$ grid cells for WFDS_9977 version and $100 \mathrm{~mm}, 50 \mathrm{~mm}$ and $37.5 \mathrm{~mm}$ grid cells for FDS 6.2.0 version.

The MLR results are compared for the three simulations of the $2.25 \mathrm{~m}$ Douglas fir tree with WFDS_9977 and FDS 6.2.0 in Figure 1. For both versions of the physics based model, the results

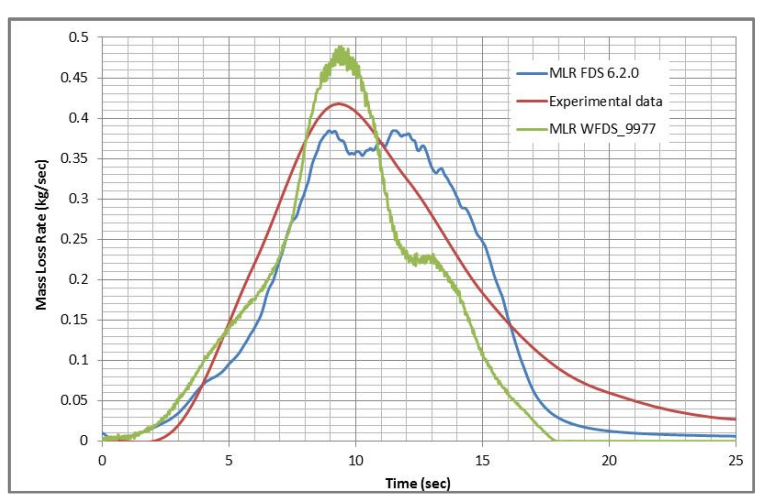

Figure 2. MLR results comparison with experimental data (Mell et al, 2009) - both numerical results are shifted by 1.5 sec. 
from $50 \mathrm{~mm}$ grid and $37.5 \mathrm{~mm}$ converge. So convergence is deemed to have obtained with $50 \mathrm{~mm}$ grid. Grid convergence is also observed in the HRR data from both FDS and WFDS simulations at $50 \mathrm{~mm}$ grid. However the trends are different: in WFDS only the peak appears to be sensitive whilst in FDS the as the grid is reduced from $100 \mathrm{~mm}$ to $50 \mathrm{~mm}$ the peak is delayed with a lower, but much longer duration of peak burning rate.

The MLR results from grid converged simulations (where $50 \mathrm{~mm}$ grid cells are used) of the $2.25 \mathrm{~m}$ Douglas fir tree with the experimental data in Figure 2. The simulation results are shifted towards the left by $1.5 \mathrm{sec}$ to roughly match the peak. It can be observed that the area under the curve is roughly the same. The averaged total mass loss from nine experiments was $3.62 \mathrm{~kg}$. The mass loss rate is exactly the same for FDS 6.2.0 simulation. However it is roughly $12 \%$ less while the simulation is conducted with WFDS_9977. The discrepancy may be due to the fact that different fuel representation are used for WFDS simulation.

Figure 3 shows snapshots of simulations of a $2.25 \mathrm{~m}$ tall tree using WFDS' companion graphical output software Smokeview (Forney, 2008). Figures represent temperature slices to show the gas-phase temperature at various instances of time after ignition.

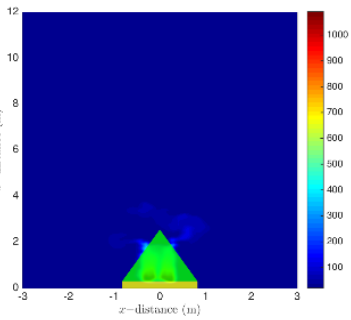

(a) $4.9 \mathrm{sec}$

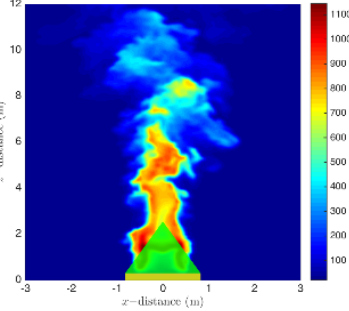

(b) $11.9 \mathrm{sec}$

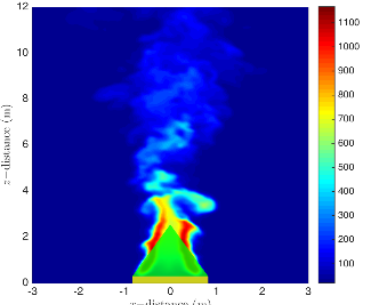

(b) $14.9 \mathrm{sec}$

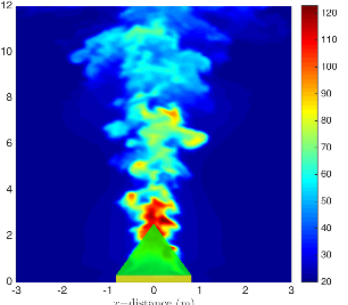

(d) $19.9 \mathrm{sec}$

Figure 3. Graphical representation of Douglas fir tree burns simulation. The results from the WFDS simulation is depicted to show the gas-phase temperature at various instances of time after ignition.

\subsection{Forest floor and canopy fire- semi-quantitative}

With successful quantitative simulation of the burning $2.25 \mathrm{~m}$ Douglas Fir tree along with achieving numerical convergence, we now attempt to model a scenario where forest floor fire interacts with tree canopy. We have used WFDS due to its lesser computational resource requirement. As FDS needs 100,000 particles of each type of vegetation parts per unit volume, it needs enormous computational resources to model a number of trees.

We have modelled a forest of $2.25 \mathrm{~m}$ Douglas Fir trees sitting on a grassland. Therefore the forest canopy height $(\mathrm{CH})$ is $2.25 \mathrm{~m}$. This is absolutely a hypothetical scenario (may not be practical, though possibly it can be a model of a plantation) to assess whether fire progression from the surface to the crown can be simulated. The simulation is conducted with a narrow domain. The validity of such simulation approach was demonstrated by Linn et al (2012). The simulation domain is $124 \mathrm{~m}$ long, $8 \mathrm{~m}$ wide as shown in Figure 4. The inlet is prescribed as power law (1/7) model of the atmospheric boundary layer (ABL) with a wind speed of $3 \mathrm{~m} / \mathrm{s}$ at $2 \mathrm{~m}$. The two lateral edges are modelled as periodic, that is the left and right boundaries are constrained to be equal. Therefore the simulation can be thought of as an infinite side-by-side tiling of similar domains. The outlet and top of the domain are modelled as lines of constant pressure. The burnable grass plot (37 m long) starts $45 \mathrm{~m}$ (in the longitudinal direction) from the inlet. Four longitudinal columns of Douglas Fir trees are modelled. The crown was approximated as cones and the trunk as cylinders. For simplicity the crowns are modelled only as needles with $2.2 \mathrm{~kg} / \mathrm{m}^{3}$ bulk density. Alternate columns had 16 and 17 trees in a staggered fashion. The columns are $2 \mathrm{~m}$ apart and within the column, the trees are also $2 \mathrm{~m}$ apart. Moinuddin et al. (2016) showed that for grassfire, $250 \mathrm{~mm}$ grid

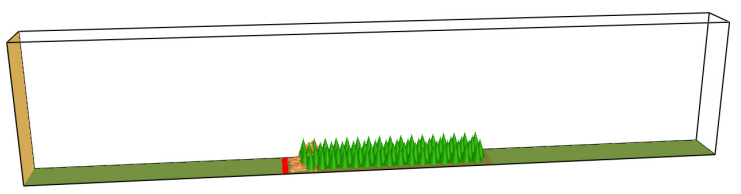

Figure 4. Graphical representation of surface firecrown interaction simulation. provides grid convergence rate of spread. As $50 \mathrm{~mm}$ grid for forest fire simulation is extremely expensive, in this study $100 \mathrm{~mm}$ grid is used. A sensitivity study is conducted with shorter forest length and domain size with $50 \mathrm{~mm}$ grid. It is found that while the size (HRR) of the forest fire are roughly the same, the transition from the surface fire to crown fire occurs $\sim 13 \mathrm{sec}$ earlier. 
Prior to actual simulation of fire line spread, a precursor simulation was carried out to generate an initial wind field within the simulation domain. Upon establishment of a steady state wind field, a lateral line fire of $1 \mathrm{~m}$ width is ignited with $500 \mathrm{~kW} / \mathrm{m}^{2}$ heat release rate per unit area (Fig 4).

The domain size was tested in relation two ways:

- Domain length - especially downstream of the forest space with $24 \mathrm{~m}$ and $42 \mathrm{~m}$

- Domain height $(\mathrm{H})$ - with $10 \mathrm{~m}, 15 \mathrm{~m}, 20 \mathrm{~m}$ and $25 \mathrm{~m}$ height

HRR vs time results (Fig 5) of four simulations shows that the results are not affected by $24 \mathrm{~m}$ and $42 \mathrm{~m}$ space downstream of the forest indicated by the same surface to forest fire transitions and similar growth rate. However domain height does have a significant effect shown by the HRR values 40 secs after ignition. However no significant difference is observed between $20 \mathrm{~m}$ and $25 \mathrm{~m}$ domain height cases (representing $\sim 9$ and 11 $\mathrm{H} / \mathrm{CH}$ ratio). This indicates that a domain height roughly 8 times of the crown height may be sufficient. The results below presented are from $25 \mathrm{~m}$ domain height case.

In Fig 6, fire front location and HRR as a function of time are presented. A fire front is determined

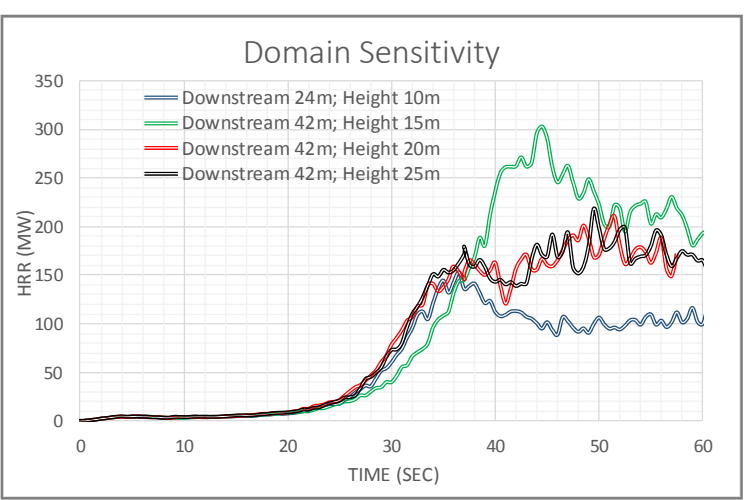

Figure 5. HRR vs time results from sensitivity analysis. based on HRR data. The definition of the instantaneous centreline flame front is the xz-location of the point at which $90 \%$ of the total HRR is obtained. In Fig 6(a) the red line is a least-squares regression fit to the surface fire behaviour and the blue line is a fit to the crown fire data. Surface fire and transition to crown propagation is clearly visible between 30 to 40 sec.

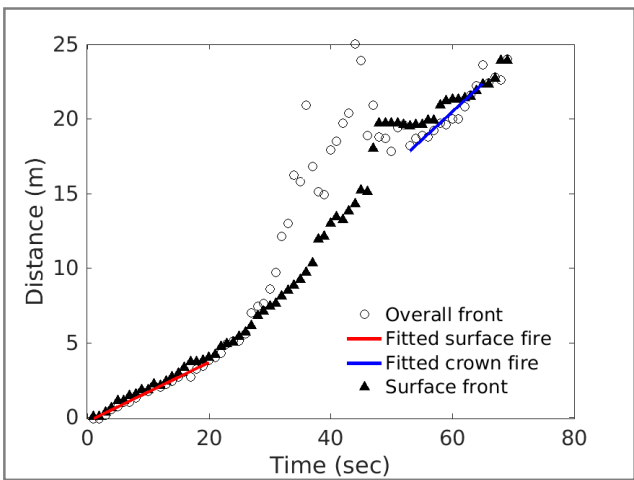

(a) Fire front location

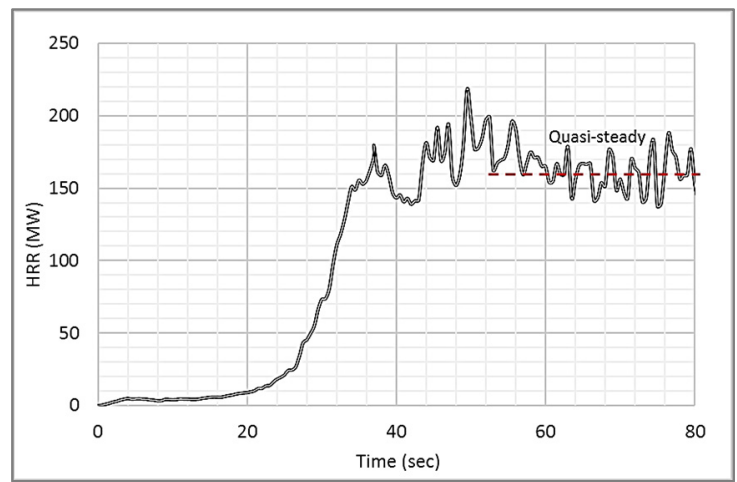

(b) HRR

Figure 6. Finding quasi-steady rate of spread of crown fire

Deciding when the fire has completely reached a crown phase is ambiguous. HRR vs time data in Fig 6(b) shows that roughly $53 \mathrm{sec}$ after the ignition of line fire a quasi-steady period emerges which corresponds well with Fig 6(a).

Visual representation of flames impacting on the crown and during quasi-steady period is shown in Fig 7. From the isosurfaces of HRR at $200 \mathrm{~kW} / \mathrm{m}^{3}$ (eg Fig 7) it appears as if the surface fire transitions up to the crown, then transitions back down again at some later time. The surface fire, as measured by large HRR at the surface, appears to propagate fairly uniformly. The isosurfaces of heat release rate associated with surface burning are probably difficult to visually distinguish from the isosurfaces of heat release rate associated with crown material burning. Because the surface fire continues underneath the crown fire, this is a supported crown fire. That is, the surface fire puts energy into the crowns to sustain the burning of the crown material. (Dupuy

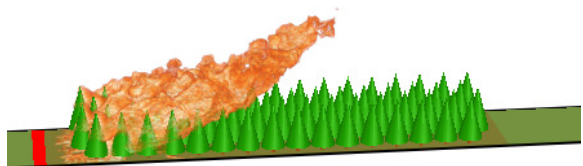

(a) Flame upon impacting the crown

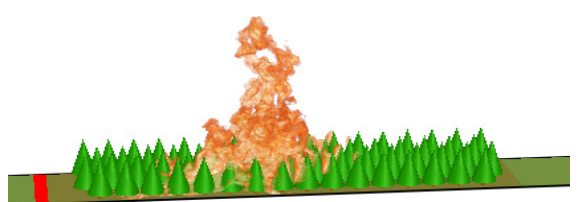

(b) Quasi-steady flame propagation

Figure 7. Visual representation flame propagation 
and Morvan, 2005). Overall many features are qualitatively in agreement with other crown fire studies (eg experiments of Cruz et al, 2013). We can therefore be confident that crown fire simulations are possible with the physics-based model.

\section{CONCLUSIONS}

This study is an initial step into understanding the capabilities of physics-based models FDS and WFDS establishing its capability of producing grid-converged results for fuel element models. A 2.25 m Douglas fir tree burning experiment conducted at NIST has been used to benchmark models' capability. Both models produced grid converged results of both mass loss rate and heat release rate which is a large step forward from its version 4. In the second step of the study a scenario where forest floor fire interacts with tree canopy is modelled using WFDS. In this forest floor fire is modelled using boundary fuel model whilst the forest is modelled as fuel elements. The simulation shows that WFDS can qualitatively predict propagation of surface fire to the forest canopy. From the analysis of simulation data, it appears that the surface fire continues underneath the crown fire. Other researchers also reported this kind of supported crown fire. After establishment of a crown fire, a quasi-steady propagation is observed. Therefore there is potential that the rate of spread of crown fire could be determined using a physics based model. Future work will consider changing the properties of fuels so that simulation of native Australian vegetation can be conducted.

We stress that these simulation results are for a very particular set of parameters and the numerical results may be sensitive to parameters not varied in this study. Obviously further studies and validation against observed crown fires are required before any operational correlations can be constructed. Such a validation study would need to compare simulations of extreme fire scenarios to field observations of wild fires. Eventually it is hoped that this work may lead to the determination of rate of spread for crown fire as a function of fuel and atmospheric characteristics.

The largest drawback of physics based simulations remains the large computational time due to the extremely fine grid sizes required. However, instead of LES turbulence model, simpler one-equation model and a simple linear parameterisation of thermal degradation model can be used to reduce some of the computational effort.

\section{ACKNOWLEDGMENTS}

We wish to acknowledge the financial support given by Bushfire and Natural Hazard Cooperative Research Centre (BNHCRC), Melbourne, Australia. The authors wish to thank Dr William Mell from US Forest Department for helpful discussion and making necessary changes in the WFDS source code.

\section{REFERENCES}

Cruz. M. G., McCaw, W. L., Anderson, W. R., Gould, J. S. (2013). Fire behaviour modelling in semi-arid mallee-heath shrublands of southern Australia. Environmental Modelling \& Software, 40: 21-34.

Dupuy, J.L. and Morvan, D. (2005). Numerical study of a crown fire spreading toward a fuel break using a multiphase physical model. International Journal of Wildland Fire, 14(2):141-151.

Forney, G.P. (2008). Smokeview (Version 5) - A Tool for Visualizing Fire Dynamics Simulation Data Volume I: User's Guide, NIST Special Publication 1017-1 National Institute of Standards and Technology, U.S. Department of Commerce, Gaithersburg, MD, July 2008.

Linn, R.R. Canfield, J. M., Cunningham, P., C Edminster, Dupuy, J. L. and Pimont, F. (2012). Using periodic line fires to gain a new perspective on multi-dimensional aspects of forward fire spread. Agricultural and Forest Meteorology, 157:60-76.

McGrattan, K.B., Klein, B., Hostikka, S., and Floyd, J (2008). Fire Dynamics Simulator Users Guide. NIST Special Publication 1019-5, National Institute of Standards and Technology, U.S. Department of Commerce, Gaithersburg, MD, January 2008.

Mell, W., Maranghides, A., McDermott, R., Manzello, S.L. (2009). Numerical simulation and experiments of burning Douglas Fir trees. Combustion and Flame 156, 2023-2041.

Mell, W., Jenkins, M.A., Gould, J. and Cheney, P. (2007). A physics-based approach to modelling grassland fires, International Journal of Wildland Fire, 16, 1-22.

Moinuddin, KAM , Prasannan, K, Lalunio, R and Thorpe, G (2010). Numerical modelling of fire spread in landscapes. Proceedings of 8th Asia-Oceania Symposium for Fire Science \& Technology, pp 1-11.

Moinuddin, K. A. M., Sutherland, D, Mell, W. (2017). Parametric Study of Grassfire using a Physics Based Model. International Journal of Wildland Fire (submitted)

Morvan, D and Dupoy, J. L. (2004). Modeling the propagation of a wildfire through a Mediterranean shrub using a multiphase formulation Combustion and Flame 138, 199-210. 